\title{
FATIGUE LIFE PREDICTION OF ALUMINIUM PROFILES FOR MECHANICAL ENGINEERING
}

\author{
Tomasz Tomaszewski, Janusz Sempruch
}

University of Technology and Life Sciences in Bydgoszcz, Faculty of Mechanical Engineering, Bydgoszcz, Poland

e-mail: tomaszewski@utp.edu.pl

\begin{abstract}
The study presents a method to determine the $\sigma_{a}-N$ curve (high cycle fatigue) for profiles made of AW-6063 T6 aluminium alloy. Experimental material data for a mini specimen taken directly from the tested item and selected empirical correlations allowing for a size effect have been used. A model yielding the lowest relative error of estimating the fatigue life is presented.
\end{abstract}

Keywords: aluminium profile, high-cycles fatigue, mini specimen, size effect

\section{Introduction}

Modular frame systems made of aluminium profiles are an important innovation of the last fifteen years in the science of structures. They are applied in many industries, including mechanical engineering. Selecting a suitable profile size due to its strength and durability requires knowledge on fatigue, material and profile properties.

The $\sigma_{a}-N$ curve can be determined for a limited fatigue life using an analytical method based on commonly accepted quantities defining the curve (slope coefficient of the $\sigma_{a}-N$ curve in the range of high cycles $(m)$

$$
\log \sigma_{a}=\frac{1}{m} \log N=b
$$

and knee point for a specific group of materials $\left(\sigma_{A K}, \tau_{A K}\right)$ - Fig. 1) or using experimental tests (Kocanda et al., 1997). Comparison of fatigue characteristics of some selected materials are presented in the paper by Kurek et al. (2014).

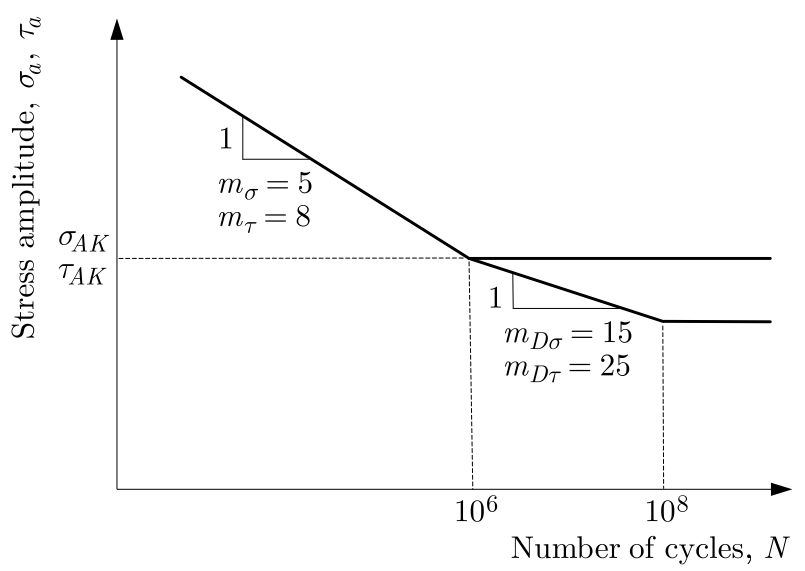

Fig. 1. Specific $\sigma_{a}-N$ curve estimated from FITNET procedure (FITNET, 2006) 
Examplary records of the analytical approach to estimate the fatigue life are available in one of the FITNET procedures (path $2 b$ ). The approach includes analytical determination of the $\sigma_{a}-N$ curve at constant amplitude loads. The knee point is taken for $N_{o}=10^{6}$ cycles and stress determined from the equation (FITNET, 2006):

— for normal stress

$$
\sigma_{W}=f_{W, \sigma} R_{m}
$$

— for shear stress

$$
\tau_{W}=f_{W, \tau} R_{m}
$$

where $f_{W, \sigma}, f_{W, \tau}$ are coefficients determined by the material and stress type, $R_{m}$ is tensile strength.

Stress values $\sigma_{A K}, \tau_{A K}$ (see Fig. 1) are calculated based on the product of stresses $\sigma_{W}, \tau_{W}$ and the correction factor allowing for the effect of selected factors on fatigue life (size, notch, roughness and average stress). The fatigue $\sigma_{a}-N$ curve is estimated from the fatigue life range allowing for the slope coefficient $m$ in accordance with Fig. 1.

For the analytical method, the results of the fatigue life estimation may be burdened by a high error resulting from natural high scatter of input values available in the literature. Figure 2 shows a histogram of the coefficient $m$ distribution compared to the gamma distribution for smooth steel specimens. Distribution width correlates to quality of the analytical test of the approximation, rendering the method inaccurate.

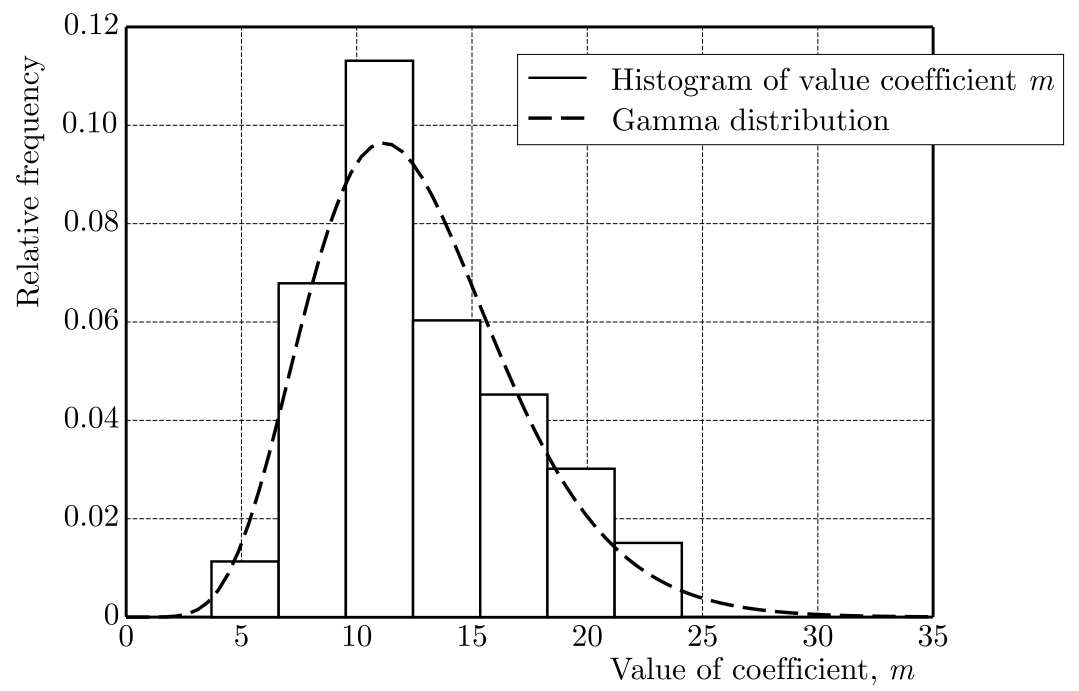

Fig. 2. Example of the distribution of the coefficient $m$ for a construction steel and smooth specimen normal stress (Strzelecki and Sempruch, 2014)

The experimental approach is characterized by a significantly greater accuracy and is discussed in this work for aluminium profiles.

Aluminium profiles are manufactured in the extrusion process. Material properties change as a result of extrusion. The implementation of experimental methods for aluminium profiles often does not allow one to take full dimensional standard specimens. In the case of profiles, identification of prefabricated element properties requires non-standard specimens with reduced dimensions (referred to as mini specimens) due to limited dimensions of the tested item.

Figure 3 shows examplary applications of profiles and specimens taken directly from the profile. The purpose of the study is to discuss the method to determine strength and fatigue properties of profiles to further determine fatigue life and fatigue limit. 
(a)

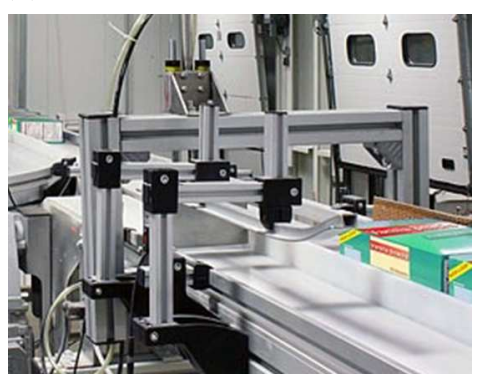

(b)

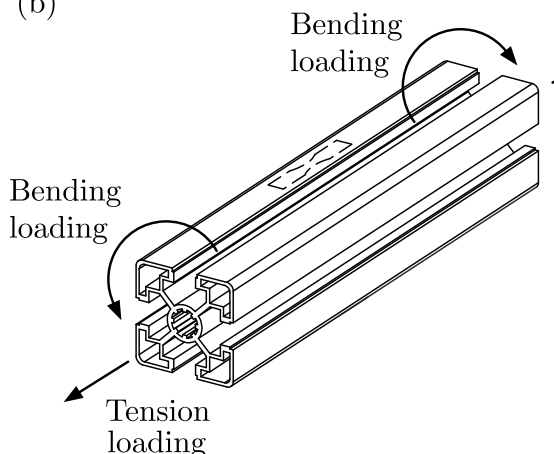

(c)

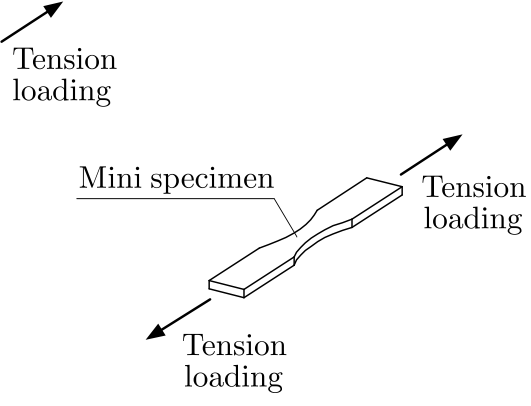

Fig. 3. Aluminium profiles: (a) application, (b) prevailing operational loads, (c) specimen for material tests

\section{Test methods for aluminium mini specimens}

\subsection{Test stand}

General strength and fatigue tests discussed in this study were performed on a standard servo-hydraulic testing machine (Instron 8874) - Fig. 4a. The machine features a dynamometer operating at $\pm 25 \mathrm{kN}$ force and $100 \mathrm{~N} \cdot \mathrm{m}$ torque. Monotonic tests were carried out using Instron 2620 Series dynamic strain gauge extensometer $(12.5 \mathrm{~mm}$ gauge length with a travel of $\pm 5 \mathrm{~mm}$ ).

As a part of verification of the test method for mini specimens, the tests were performed on a testing machine of the author's own design - Fig. 4b (Tomaszewski and Sempruch, 2014a).

(a)

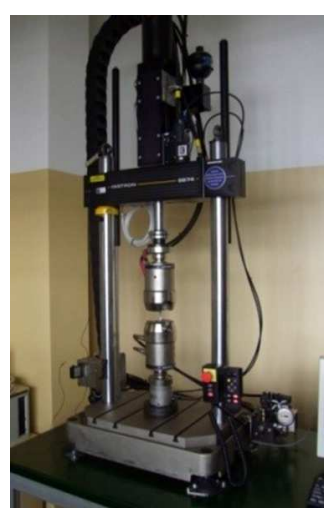

(b)

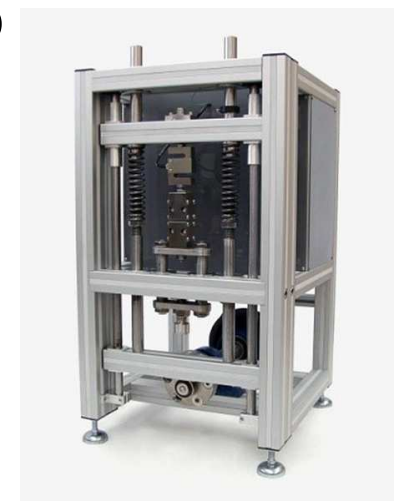

Fig. 4. Test stand used in the study: (a) Instron 8874, (b) own design

\subsection{Applied loads}

The fatigue properties were determined at a high-cycle fatigue regime. The tests were performed at controlled stress. The $\sigma_{a}-N$ curve was plotted based on 6 load levels for a total of 15 specimens. Test conditions conformed to standard requirements (PN-74/H-04327). A macro crack was used as a fatigue test end criterion. The tests were carried out at $5 \mathrm{~Hz}$ load change frequency, resulting from the technical capabilities of the servo-hydraulic testing machine used. The upper load level was limited by the experimental yield point $\left(R_{0.2}=226 \mathrm{MPa}\right)$.

The tested specimen featured low resistance to buckling, thus the load cycle was changed at a constant tensile component (stress ratio $>0$ ).

\subsection{Fatigue test specimen}

Flat specimens with variable width of the measured section were used throughout the tests (Fig. 5). The specimen size was determined by its ability to be taken from the specific profile 
(Fig. 6). The value $t$ was determined by the profile wall thickness. Mini specimens were prepared by machining (milling). No additional working was used, e.g. grinding, polishing.

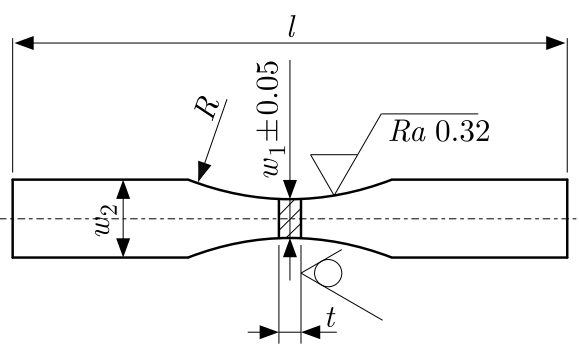

Fig. 5 . Specimen used in high-cycle fatigue tests: $t=1.58 \pm 0.03, w_{1}=3.5, w_{2}=7, l=50, R=25$

\section{Example tests}

\subsection{Material and material identification}

Experimental tests were performed on AW-6063 T6 aluminium alloy specimens. The tested material was taken directly from the profiles manufactured in the extrusion process. The fatigue properties were affected by a surface finish of the prefabricated element, thus the material was taken from anodized profile (most common profile surface treatment). Figure 6 shows the profile geometry.
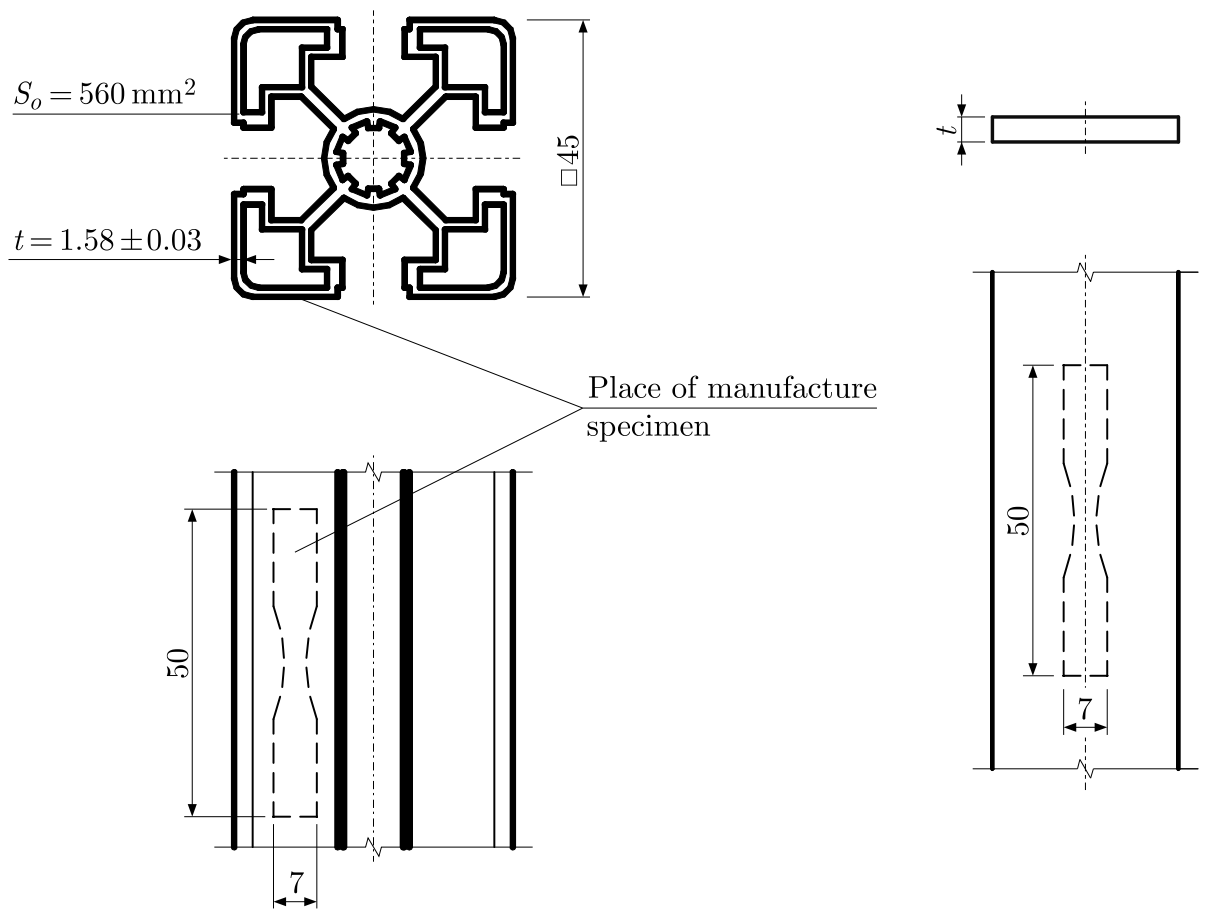

Fig. 6. Size of specimen taken form: (a) profile, (b) flat bar

Mechanical properties were determined in monotonic load conditions as per (PN-EN ISO 6892-1:2010). See Table 1 for results. The results show a low standard deviation. Table 2 shows selected material properties in accordance with the manufacturer's specification. Figure 7 shows static characteristics $(\varepsilon-\sigma$ curve). 
Table 1. Mechanical properties of AW-6063 T6 aluminium alloy (anodized) - mini specimen $\left(S_{o}=5.5 \mathrm{~mm}^{2}\right)$

\begin{tabular}{|c|c|c|c|c|c|c|}
\hline No. & $R_{m}[\mathrm{MPa}]$ & $R_{0.2}[\mathrm{MPa}]$ & $R_{u}[\mathrm{MPa}]$ & $E[\mathrm{MPa}]$ & $A[\%]$ & $Z[\%]$ \\
\hline \hline 1 & 250 & 226 & 281 & 69319 & 16.8 & 29.6 \\
\hline 2 & 249 & 225 & 271 & 67532 & 11.2 & 22.1 \\
\hline 3 & 250 & 226 & 270 & 69632 & 12.8 & 23.1 \\
\hline 4 & 251 & 227 & 293 & 67664 & 12 & 32.4 \\
\hline 5 & 250 & 225 & 275 & 69181 & 12.8 & 24.4 \\
\hline Average value & 250 & 226 & 278 & 68665 & 13.1 & 26.3 \\
\hline Standard deviation & 0.7 & 0.8 & 9.4 & 989 & 2.2 & 4.4 \\
\hline
\end{tabular}

Table 2. Mechanical properties of AW-6063 T6 aluminium alloy (anodized) - manufacturer's data

\begin{tabular}{|c|c|c|c|}
\hline$R_{m}[\mathrm{MPa}]$ & $R_{0.2}[\mathrm{MPa}]$ & $E[\mathrm{MPa}]$ & $A[\%]$ \\
\hline \hline 245 & 195 & 70000 & 10 \\
\hline
\end{tabular}

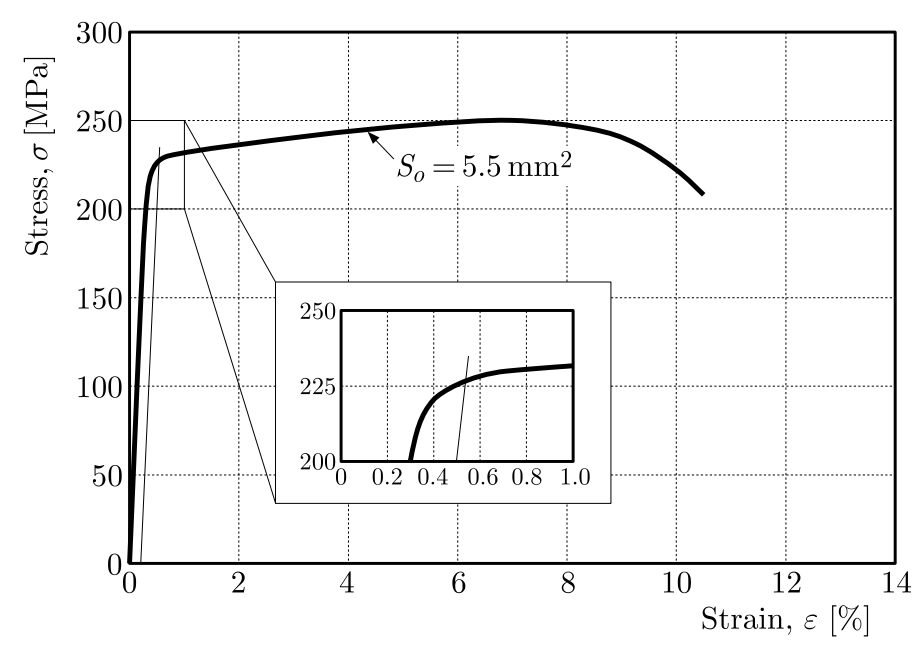

Fig. 7. Stress-strain diagram of a specimen taken from the anodized profile made of AW-6063 T6 aluminium alloy

\subsection{Test results}

Experimental tests aimed to determine the coefficient $m$. Fatigue life was determined at selected stress amplitude levels based on the tests of the mechanical property. Table 3 shows the test results.

The data are approximated to a linear equation corresponding to $50 \%$ likelihood of specimen failure. Figure 8 shows the diagram in a bi-logarithmic system. Experimental points and solid line corresponding to linear regression are shown compared to the confidence interval (grey area). The regression line shows a high coefficient of determination $R^{2}$. The coefficient $m$ for the analysed aluminium alloy taken from the profile is 7.35 .

The effect of the cross-section must be taken into account to consider the curve as universal and reliable for the group of profiles. It is thus necessary to determine the correlation between the positions of each curve plotted for the specimens with different cross-sections. The studies presented in (Tomaszewski et al., 2014) show that within the high-cycle fatigue range, the $\sigma_{a}-N$ curves plotted for the mini specimen $\left(S_{o}=3.5 \mathrm{~mm}^{2}\right)$ and the standard specimen $\left(S_{o}=28 \mathrm{~mm}^{2}\right)$ made of AW-6063 T6 aluminium alloy (from flat sections) are parallel (Table 4). This is indicated by a similar slope coefficient of the regression line $(m \approx$ const $)$ and statistical parallelism tests. 
Table 3. Test results for fatigue life (PN-74/H-04327) for mini specimen $\left(S_{o}=5.5 \mathrm{~mm}^{2}\right)$ made of AW-6063 T6 aluminium alloy taken from the profile

\begin{tabular}{|c|c|c|}
\hline \multicolumn{2}{|c|}{ Stress, $R=0.1$} & \multirow{2}{*}{$\begin{array}{c}\text { Fatigue life, } \\
N \text { [cycles] }\end{array}$} \\
\hline$\sigma_{a}[\mathrm{MPa}]$ & $\sigma_{\max }[\mathrm{MPa}]$ & \\
\hline \multirow{3}{*}{97.9} & \multirow{3}{*}{220} & 36855 \\
\hline & & 38946 \\
\hline & & 48011 \\
\hline \multirow{3}{*}{89} & \multirow{3}{*}{200} & 88337 \\
\hline & & 94717 \\
\hline & & 107079 \\
\hline \multirow{3}{*}{80.1} & \multirow{3}{*}{180} & 146563 \\
\hline & & 166113 \\
\hline & & 180036 \\
\hline \multirow{3}{*}{75.7} & \multirow{3}{*}{170} & 305253 \\
\hline & & 365625 \\
\hline & & 429974 \\
\hline 66.8 & 150 & 604432 \\
\hline \multirow{2}{*}{62.3} & \multirow{2}{*}{140} & 932905 \\
\hline & & 1182165 \\
\hline
\end{tabular}

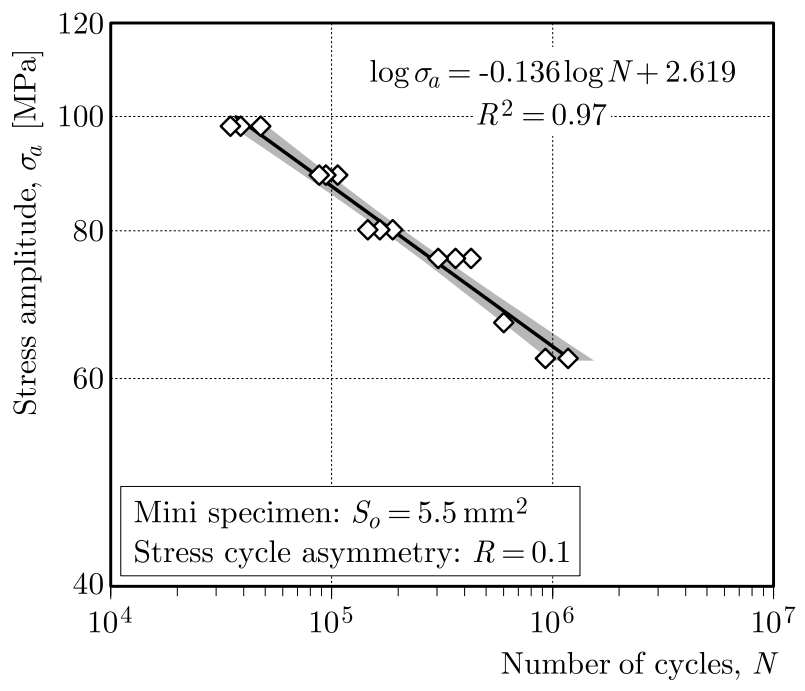

Fig. 8. Graphical representation of the $\sigma_{a}-N$ curve in the high-cycle fatigue regime for AW-6063 T6 aluminium alloy

Table 4. Comparison of the linear regression coefficients of the $\sigma_{a}-N$ curve for AW-6063 T6 aluminium alloy (from flat section)

\begin{tabular}{|c|c|c|c|}
\hline $\begin{array}{c}\text { Cross-sectional } \\
\text { area }\end{array}$ & \multicolumn{2}{|c|}{$\begin{array}{c}\text { Regression line, } \\
R=0.1\end{array}$} & $\begin{array}{c}\text { Coefficient of } \\
\text { determination }\end{array}$ \\
\hline \hline$S_{o}\left[\mathrm{~mm}^{2}\right]$ & $1 / m$ & $b$ & $R^{2}$ \\
\hline 28 & -0.078 & 2.319 & 0.97 \\
\hline 3.5 & -0.078 & 2.374 & 0.93 \\
\hline
\end{tabular}


The flat bars were shaped in the same conditions as the profiles. The size effect for aluminium alloy is not affected by the stress amplitude (load). With a known coefficient $m$ and the size effect for the specific group of structural materials, the fatigue properties can be determined for the entire family of the profiles.

\section{Size effect}

The size effect defines the relationship between the fatigue properties of the material or structural element and its size. The material strength decreases with an increase in size of the tested item subject to monotonic or fatigue loads (Carpinteri et al., 2009). The reduction in strength is affected by factors related to a random distribution of defects in the material, shape and type of load and the effect of technological processes during production.

The size effect is commonly defined as a ratio of strength properties of a specimen with specific cross section and the standard specimen

$$
K_{Z}=\frac{\sigma_{(-1)}}{\sigma_{(-1) n}} \quad K_{H C}=\frac{\sigma}{\sigma_{n}} \quad K_{S}=\frac{R_{m}}{R_{m n}}
$$

where $\sigma_{(-1)} / \sigma / R_{m}$ is the fatigue limit/fatigue strength/tensile strength of the specimen with any cross-section, $\sigma_{(-1) n} / \sigma_{n} / R_{m n}$ is the fatigue limit/fatigue strength/tensile strength of the normative specimen (cross-section $20-80 \mathrm{~mm}^{2}$ ) while maintaining the same material. Figure 9 shows schematic relation between the cross-sectional area and the coefficient $K$.

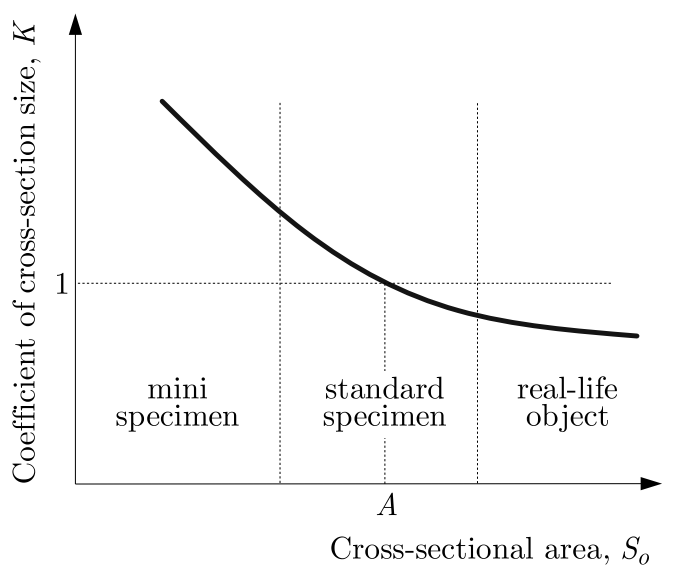

Fig. 9. Schematic relation between the cross-sectional area and the coefficient of cross-section size

Aluminium alloys show changes in fatigue properties depending on the cross-section of the tested specimen. The changes were verified based on the experimental tests of the coefficient $K$ (Eq. (4.1), Table 5) for AW-6063 T6 aluminium alloy taken from flat bars (Tomaszewski and Sempruch, 2015).

Table 5. Comparison of the coefficients $K_{S}$ and $K_{H C}$ (Tomaszewski and Sempruch, 2015)

\begin{tabular}{|c|c|c|}
\hline $\begin{array}{c}\text { Cross-sectional } \\
\text { area, } S_{o}\left[\mathrm{~mm}^{2}\right]\end{array}$ & $K_{S}$ & $K_{H C}$ \\
\hline \hline 3.5 & 1.150 & 1.131 \\
\hline $28^{*}$ & 1 & 1 \\
\hline
\end{tabular}

* equivalent point $A$ in Fig. 9

Notwithstanding the origin of the size effect, the fatigue life is estimated from empirical correlations between the coefficient $K$ value and a specific specimen dimension (e.g. diameter $d$ ). 
Table 6 shows selected size effect correlations allowing for the range of application and the author of the given proposal. Due to the analysis of tests for specimens with rectangular cross-section, the correlations are examined for the cross-sectional area $S_{o}$.

Table 6. Quantitative correlation between cross-section coefficients $K_{Z}$, author's study based on (Shigley et al., 2004)

\begin{tabular}{|c|c|c|}
\hline$K_{Z}$ & Range $[\mathrm{mm}]$ & Author \\
\hline \hline$\frac{0.947}{1-0.406 / d}$ & $3.2 \leqslant d \leqslant 48$ & Moore \\
\cline { 1 - 2 } $0.931\left(1+\frac{0.014}{0.1+(d / 25.4)^{2}}\right)$ & $d \leqslant 50$ & Heywood \\
\cline { 1 - 2 } 1 & $d \leqslant 8$ & $\begin{array}{c}\text { Shigley } \\
\text { and } \\
\text { Mitschke }\end{array}$ \\
\cline { 1 - 2 } $1.189 d^{-0.097}$ & $d \leqslant 250$ & Roark \\
\hline 0.6 & $50 \leqslant d \leqslant 230$ & \\
\cline { 1 - 2 } & &
\end{tabular}

\section{Verification example}

The purpose of the analysis is to estimate the $\sigma_{a}-N$ curve in a high-cycle fatigue regime for a selected profile based on experimental data obtained for a mini specimen. The correction coefficient of cross-section $K$ is used to shift the curve in parallel to the side of the lower fatigue life. The shift direction corresponds to a general trend known for metals, where fatigue properties decrease with an increase in the cross-sectional area.

Initial empirical size effect correlations are implemented for the fatigue limit. Since in the range of elastic deformation of the material the initiation and propagation of the fatigue crack are similar, the values presented in Table 5 can be used in the high-cycle fatigue regime.

Based on many experimental studies as well as on the author's own study (Tomaszewski and Sempruch, 2015), a change in fatigue properties manifest itself as an increase in specimens smaller than the standard specimens. The coefficient $K$ is higher than 1 in this range of specimen sizes (Table 5). Implemented empirical correlations will be analysed irrespective of the scope shown in Table 6.

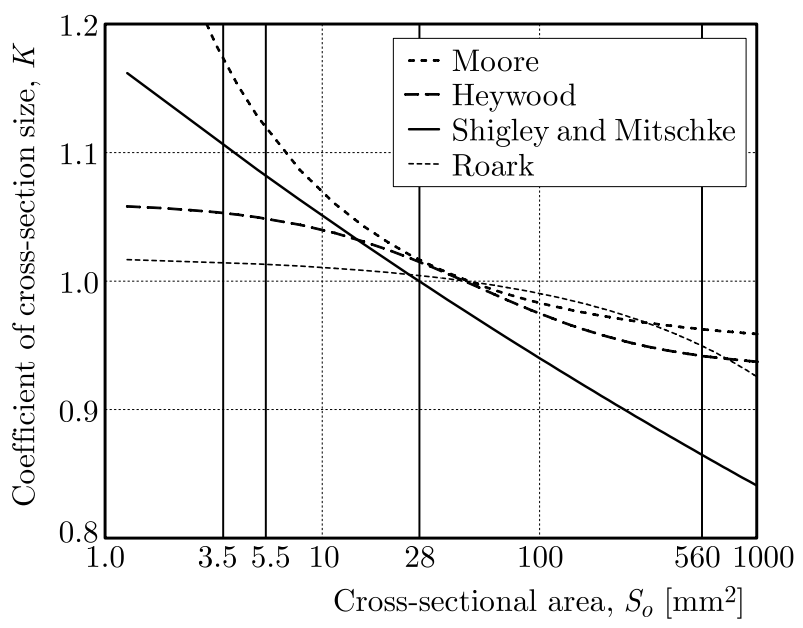

Fig. 10. Graphical comparison of the correlations of the cross-section coefficient based on Table 6 
Figure 10 shows a graphical approach regarding the analytical correlations to determine $K$ coefficient: The curves are intersected by vertical lines corresponding to selected cross-sectional areas: $3.5 \mathrm{~mm}^{2}, 5.5 \mathrm{~mm}^{2}$ (mini specimen), $28 \mathrm{~mm}^{2}$ (standard specimen), $560 \mathrm{~mm}^{2}$ (profile).

The analysed correlations do not allow for the material constants that are difficult to determine, and thus are easy to apply within the scope of basic engineering calculations. Allowing for the scatter of experimental results, the material data can be found in the model based on the weakest link theory (Weibull, 1949), fractal approach (Carpinteri et al., 2009) or energy law (Bažant, 1984). Verification of correct implementation is described in (Tomaszewski et al., 2014).

Quantitative assessment of the degree of conformity of empirical and analytical data (based on the correlations in Table 5) is performed for the following cross-sectional areas: 3.5 and $28 \mathrm{~mm}^{2}$. It results from the availability of experimental data and material properties similar to the target aluminium alloy the profile is made of. Table 7 shows the coefficient $K_{H C}$ determined based on analytical correlations and experimental data. The relative error estimated from the following equation is used in the quantitative analysis

$$
\delta=\frac{\sigma_{e x}-\sigma_{c a l}}{\sigma_{e x}} \cdot 100
$$

where $\sigma_{e x}$ is the experimental fatigue limit for a specific fatigue life, $\sigma_{c a l}$ is the analytical fatigue limit for a specific fatigue life.

Table 7. Comparison of cross-section coefficient values determined based on analysed empirical correlations and experimental tests

\begin{tabular}{|c|c|c|c|c|c|}
\hline \multirow{2}{*}{$\begin{array}{c}\text { Cross-sectional } \\
\text { area, } S_{o}\left[\mathrm{~mm}^{2}\right]\end{array}$} & \multicolumn{5}{|c|}{$K_{H C}$} \\
\cline { 3 - 6 } & Moore & Heywood & $\begin{array}{c}\text { Shigley and } \\
\text { Mitschke }\end{array}$ & Roark & $\begin{array}{c}\text { Experimental tests } \\
\text { (Tomaszewski and } \\
\text { Sempruch, 2015) }\end{array}$ \\
\hline \hline 3.5 & 1.173 & 1.053 & 1.106 & 1.014 & 1.131 \\
\hline 28 & 1.016 & 1.015 & 0.999 & 1.004 & 1 \\
\hline
\end{tabular}

Table 8 shows the error $\delta$ determined based on equation (4.2). Application of the Roark equation does not give significant differences in the results, therefore this model will not be analyzed. Moore, Shigley and Mitschke equations have been used due to discrepancies in the obtained coefficient $K_{H C}$. Results from the Moore equation estimate higher $K_{H C}$ values corresponding to a higher fatigue life by positioning the $\sigma_{a}-N$ curve on the unsafe side in relation to the experimental data. The situation is reversed for the Shigley and Mitschke equations, and thus the values are lower.

Table 8. Relative errors for the analysed empirical correlations

\begin{tabular}{|c|c|c|c|}
\hline Cross-sectional & \multicolumn{3}{|c|}{ Relative error [\%] } \\
\cline { 2 - 4 } area, $S_{o}\left[\mathrm{~mm}^{2}\right]$ & Moore & Heywood & Shigley and Mitschke \\
\hline \hline 3.5 & -3.7 & 6.9 & 2.2 \\
\hline 28 & -1.6 & -1.5 & 0.0 \\
\hline
\end{tabular}

Table 9 shows the coefficient $K_{H C}$ calculated for the cross-sectional area of the mini specimen $\left(S_{o}=5.5 \mathrm{~mm}^{2}\right)$ and analysed profile $\left(S_{o}=560 \mathrm{~mm}^{2}\right)$. The $\sigma_{a}-N$ curve for the mini specimen has been shifted in parallel by the value of the calculated coefficient $K_{H C}$. Table 10 shows coefficients of linear regression for the straight lines.

The Moore equation overestimates the values, whereas Shigley and Mitschke equations underestimate the values, thus it seems that the most correct values for the cross-sectional area of $560 \mathrm{~mm}^{2}$ are between those curves (Fig. 11). 
Table 9. Cross-section coefficient values determined based on the analysed empirical correlations

\begin{tabular}{|c|c|c|c|}
\hline Cross-sectional & \multicolumn{3}{|c|}{$K_{H C}$} \\
\cline { 2 - 4 } area, $S_{o}\left[\mathrm{~mm}^{2}\right]$ & Moore & Heywood & Shigley and Mitschke \\
\hline \hline 5.5 & 1.119 & 1.049 & 1.082 \\
\hline 560 & 0.962 & 0.942 & 0.865 \\
\hline
\end{tabular}

Table 10. Comparison of linear regression coefficients of the $\sigma_{a}-N$ curves for AW-6063 T6 aluminium alloy

\begin{tabular}{|c|c|c|c|}
\hline $\begin{array}{c}\text { Cross-sectional } \\
\text { area, } S_{o}\left[\mathrm{~mm}^{2}\right]\end{array}$ & \multirow{2}{*}{ Results } & \multicolumn{2}{|c|}{ Regression line, $R=0.1$} \\
\cline { 3 - 4 } & & $1 / m$ & $b$ \\
\hline \hline \multirow{3}{*}{5.5} & Experiment & -0.136 & 2.619 \\
\hline \multirow{3}{*}{560} & analytically - Moore & -0.136 & 2.556 \\
\cline { 2 - 4 } & analytically - Heywood & -0.136 & 2.575 \\
\cline { 2 - 4 } & analytically - Shigley and Mitschke & -0.136 & 2.534 \\
\hline
\end{tabular}

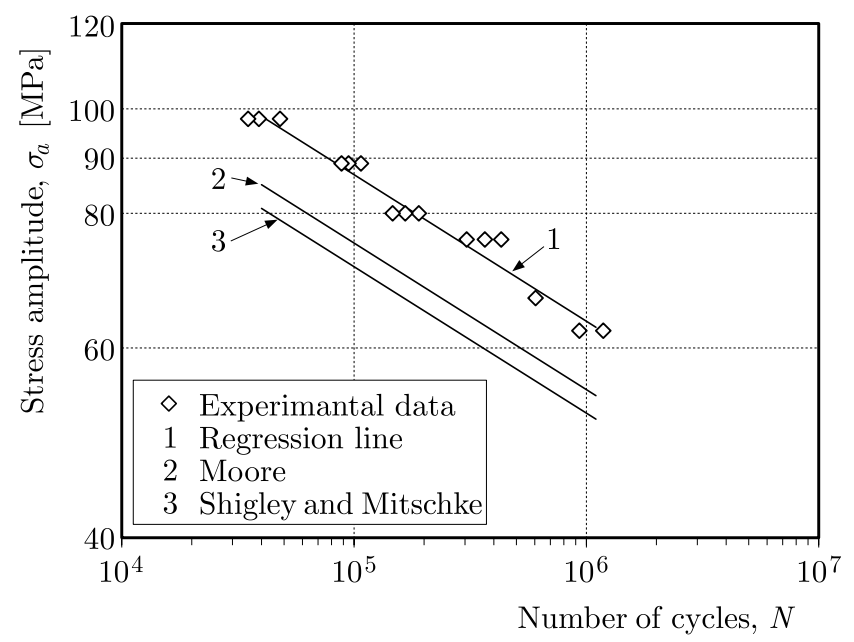

Fig. 11. Fatigue $\sigma_{a}-N$ curves plotted for the experimental data and analytical models of the size effect

A change in fatigue properties of the material or a structural element is most often analysed in the context of its fatigue life. For stress amplitudes $\sigma_{a}$ corresponding to $90 \mathrm{MPa}$ and $60 \mathrm{MPa}$, the fatigue life is determined based on the regression equation (Moore, Shigley and Mitschke model). The results have been compared with the experimental data (Table 11).

\section{Summary}

The article presents test methods to obtain material data for an aluminium profile and estimate the $\sigma_{a}-N$ curve for the actual cross-sectional area of the tested item (higher than the tested specimen). Thus, selected empirical correlations of the size effect are used in the study.

Due to the inability to obtain experimental data for the profile, the discussed correlations have been verified directly using the experimental test results for the mini specimen $\left(S_{o}=3.5 \mathrm{~mm}^{2}\right)$ and the standard specimen $\left(S_{o}=28 \mathrm{~mm}^{2}\right)$. The specimens in theory are made of the same material as the profile - AW-6063 T6 aluminium alloy. The calculated analytical $\sigma_{a}-N$ curves using Moore, Shigley and Mitschke equation for $28 \mathrm{~mm}^{2}$ cross-section yield the lowest relative error at $-3.7-2.0 \%$. 
Table 11. Differences in the fatigue life at two stress amplitude levels (90 MPa, $60 \mathrm{MPa})$ for the mini specimen $\left(S_{o}=5.5 \mathrm{~mm}^{2}\right)$ and profile $\left(S_{o}=560 \mathrm{~mm}^{2}\right)$ determined based on selected empirical correlations of the size effect

\begin{tabular}{|c|c|c|c|}
\hline \multirow{2}{*}{$\begin{array}{c}\text { Stress amplitude, } \\
\sigma_{a}[\mathrm{MPa}]\end{array}$} & \multicolumn{3}{|c|}{ Fatigue life, $N$} \\
\cline { 2 - 4 } & $\begin{array}{c}\text { Experiment } \\
S_{o}=5.5 \mathrm{~mm}^{2}\end{array}$ & $\begin{array}{c}\text { Moore } \\
S_{o}=560 \mathrm{~mm}^{2}\end{array}$ & $\begin{array}{c}\text { Shigley and Mitschke } \\
S_{o}=560 \mathrm{~mm}^{2}\end{array}$ \\
\hline \hline 90 & 77254 & 26407 & 18195 \\
\hline 60 & 1523040 & 520609 & 358715 \\
\hline
\end{tabular}

Theoretical fatigue life determined using analytical method for the profile is three times (as per Moore equation) or four times (as per Shigley and Mitschke equation) lower than for the specimen taken directly from the profile. This approach is advantageous in terms of engineering calculations, since the fatigue values obtained will be on the safe side in relation to the actual values.

\section{References}

1. BAZ̆Ant Z.P., 1984, Size effect in blunt fracture concrete, rock, metal, Journal of Engineering Mechanics ASCE, 110, 518-535

2. Carpinteri A., Spagnoli A., Vantadori S., 2009, Size effect in S-N curves: A fractal approach to finite-life fatigue strength, International Journal of Fatigue, 31, 927-933

3. Kocańda S., Szala J., 1997, Bases of Fatigue Calculation (in Polish), PWN, Warszawa

4. KureK M., Eagoda T., Katzy D., 2014, Comparison of fatigue characteristics of some selected materials, Materials Testing (Materialprufung), 56, 2, 92-95

5. FITNET FFS Procedure, 2006, European Fitness-for-Service, MK7

6. PN-74/H-04327 The study of metal fatigue. The test of axial tension - compression at constant cycle of external loads (in Polish)

7. PN-EN ISO 6892-1:2010 Metals - Tensile testing - Part 1: Test method at room temperature (in Polish)

8. Shigley J.E., Mischke C.R., Brown JR. T.H., 2004, Standard Handbook of Machine Design, 3rd Ed., McGraw-Hill

9. Strzelecki P., Sempruch J., 2014, Hybrid method for determining fatigue characteristic in high-cycle life, 20th International Conference Engineering Mechanics

10. Tomaszewski T., Sempruch J., 2014, Verification of the fatigue test method applied with the use of mini specimen, Key Engineering Materials, 598, 243-248

11. Tomaszewski T., Sempruch J., Piątkowski T., 2014, Verification of selected models of size effect based on high-cycle fatigue testing on mini specimens made of EN AW-6063 aluminum alloy, Journal of Theoretical and Applied Mechanics, 52, 4, 883-894

12. Tomaszewski T., Sempruch J., 2015, Analysis of size effect in high-cycle fatigue for EN AW-6063, Solid State Phenomena, 224, 75-80

13. Weibull W., 1949, A statistical representation of fatigue failures in solids, Transaction of the Royal Institute of Technology, $\mathbf{2 7}$ 